\title{
EDITORIAL
}

\section{Gender bias at Pediatric Research?}

\author{
Pediatric Research (2019) 86:2; https://doi.org/10.1038/s41390-018- \\ 0246-y
}

Earlier this year, an article was published in Science Magazine (http:// www.sciencemag.org/news/2018/05/men-disproportionately-winnih-s-plum-award-young-scientists). The article made reference to several instances of sexual harassment and gender bias in publishing and in the award of prestigious grants. Gender bias was present throughout the process of awarding the Early Independence Awards from the National Institutes of Health. More men were put forward by their institutions, and men were disproportionately granted the award. In December 2017, the Editor-in-Chief of the prestigious journal, Proceedings of the National Academy of Sciences (PNAS) was placed on leave after gender discrimination lawsuits which were filed in July of 2017.

We in the editorial office wondered if gender bias was present in the acceptance of articles for publication in Pediatric Research. Examining decisions on manuscripts submitted between 1 November 2017 and 9 August 2018, we assigned gender to the corresponding author by the following method: Name meanings were researched using a Google search for

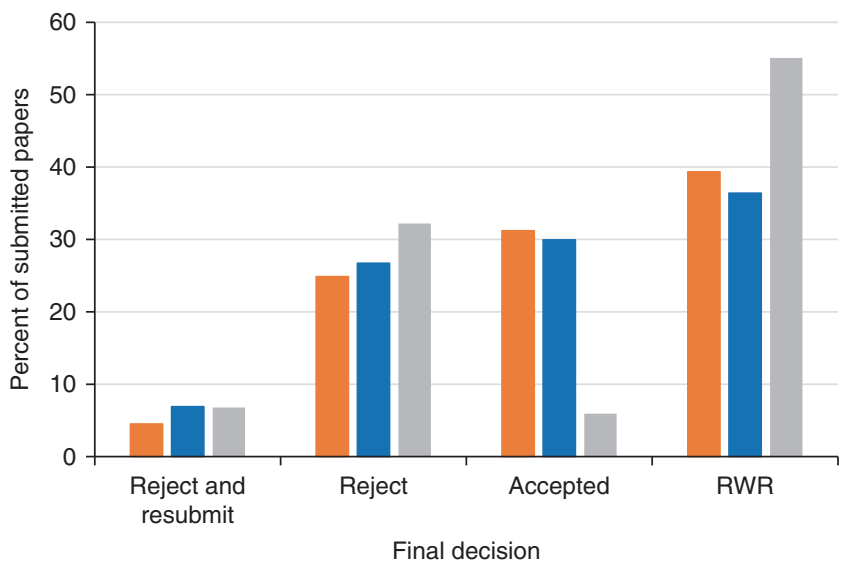

Fig. 1 Equal proportion of male and female acceptance rates at Pediatric Research. Final decisions on all manuscripts submitted to Pediatric Research from 1 November 2017 to 9 August 2018 was determined. The corresponding author of each manuscript was assigned to male or female bases on first name recognition as male or female or by picture on website. Corresponding authors whose gender could not be identified were categorized as unknown. The percentage of each decision was calculated. Orange bars-female, blue bars-male, gray bars-unknown "[name] name meaning". Website results used to determine gender included but were not limited to http://www.babynames. com, http://www.babycenter.com/baby-names, http://www.babyn amewizard.com. For corresponding authors whose gender could not be identified based on name either because the name was unisex or the name did not appear on any website, we attempted to find a picture on the corresponding author's website. If no picture was available, we assigned the author to the category of unknown. There was a significant difference between all three groups that were analyzed in a Chi-square analysis $(p=0.000017$; Fig. 1) with higher rates of reject without review and lower rates of acceptance for the unknown group. There was no difference between decisions on manuscripts authored by males and females by Chi-Square $(p=0.671)$.

We conclude that amongst corresponding authors whose names identified them as male or female, there was no difference in acceptance rates. However, amongst corresponding authors whose gender could not be identified as male or female based on their first names, the acceptance rate was lower and the reject without review higher. This low acceptance rate might be bias not on gender but on country. But more likely is reflective of the low acceptance rates of manuscripts from countries whose primary language is not English. ${ }^{1}$ To combat this issue, Pediatric Research is developing an "advisor system" as a resource to authors in these countries. The advisors are investigators who have successfully published several manuscripts with at least one in Pediatric Research. They will offer assistance at any point in the manuscript preparation and submission process. Advisors will be authors with the position of authorship negotiable. The names of the countries with advisors, the advisors' names, and email addresses will be hyperlinked in the Instructions for Authors. We will conduct another investigation in the future to assess how this system is working.

\section{ADDITIONAL INFORMATION}

Publisher's note: Springer Nature remains neutral with regard to jurisdictional claims in published maps and institutional affiliations.

Cynthia F. Bearer ${ }^{1}$ and Eleanor J. Molloy ${ }^{2}$ ${ }^{1}$ Department of Pediatrics, University of Maryland School of Medicine, Baltimore, MD 21211, USA and ${ }^{2}$ Department of Paediatrics, Trinity College, University of Dublin, Dublin, Ireland Correspondence: Cynthia F. Bearer (EICPedRes@peds.umaryland.edu)

\section{REFERENCES}

1. Lamb, C. R. \& Mai, W. Acceptance rate and reasons for rejection of manuscripts submitted to Veterinary Radiology \& Ultrasound during 2012. Vet. Radiol. Ultrasound 56, 103-108 (2015). 